\title{
Is it time to combine untargeted antifungal strategies to reach the goal of 'early' effective treatment?
}

\author{
Andrea Cortegiani* (D), Vincenzo Russotto, Santi Maurizio Raineri and Antonino Giarratano
}

A recently published retrospective study by Posteraro et al. [1] investigated the use of (1-3)- $\beta$-D-glucan (BDG) as a strategy for antifungal drug administration in patients at high risk of candidemia. The strategy consisted of the administration of antifungals (anidulafungin in most cases) to septic patients with a Candida score $\geq 3$ and a positive BDG result $(\geq 80 \mathrm{pg} / \mathrm{ml})$. This untargeted strategy led to better selection of patients, avoiding exposure to antifungals in approximately $73 \%$ of patients with negative BDG results and leading to shortened treatment duration in another $20 \%$ of patients.

Untargeted antifungal treatments (including prophylaxis, pre-emptive and empiric approaches) are the mainstay of early invasive fungal infection (IFI) management [2]. We recently published a Cochrane systematic review investigating the effects of untargeted antifungal treatment in terms of mortality and incidence of IFI in nonneutropenic critically ill patients [3]. Notably, prophylaxis resulted in IFI reduction but it may lead to exposure to antifungals for an unacceptably high proportion of patients, with associated potential adverse effects of antifungals, increased risk of resistance and costs. On the contrary, empiric treatment showed no benefit in terms of IFI reduction and mortality. We hypothesized that this observation may be due to inclusion of patients with a more advanced disease stage [4]. Moreover, many patients receiving antifungals may not need them, leading to the observed lack of benefit. The pre-emptive strategy was less investigated, with only one published randomized controlled study included in the systematic review.

According to the findings of Posteraro et al. [1], a surrogate marker-driven strategy, in association with risk factors, might represent an adequate and cost-effective approach to tailor antifungal treatment to patients who

\footnotetext{
* Correspondence: andrea.cortegiani@unipa.it

Department of Biopathology and Medical Biotechnologies (DIBIMED), Section

of Anesthesia, Analgesia, Intensive Care and Emergency, Policlinico P.

Giaccone, University of Palermo, Via del Vespro 129, 90127 Palermo, Italy
}

may benefit most. Is it time to abandon classic antifungal treatments to shift towards more pliant 'early' antifungal strategies based on risk factors and biomarkers? Data from non-randomized studies suggested that this kind of antifungal strategy might combine advantages of classic treatments with improved selection of patients and reduced exposure to antifungals, also being able to help clinicians to decide when to stop treatments [5]. There is a need for further randomized trials to answer the question of whether surrogate marker/risk factorbased antifungal strategies could be beneficial to our critically ill patients, in comparison with other (old?) untargeted treatments, in terms of efficacy, exposure to antifungals and costs.

\section{Abbreviations \\ BDG, beta-D-glucan; IFI, invasive fungal infection}

\section{Acknowledgements \\ None. \\ Funding \\ None. \\ Availability of data and materials \\ All data supporting our thoughts are available through PubMed.

\begin{abstract}
Authors' contributions
$A C$ and VR conceived the content and drafted the manuscript. SMR and AG helped to conceive the content of this letter and to revise the manuscript critically for important intellectual content. All authors read and approved
\end{abstract} the final version of the manuscript.}

\section{Competing interests \\ $A C, V R$ and SMR declare that they have no competing interests. AG received grants, fees for educational presentation and advisory board membership, without any relationship to the submitted work, from Pfizer (New York, NY, USA), Merck Sharp (Kenilworth, NJ, USA) and Gilead (Foster City, CA, USA). His institution received a grant from Gilead, Pfizer and Merck Sharp without any relationship to the submitted work.}

\section{Consent for publication}

Not applicable. 


\section{Ethics approval and consent to participate}

Not applicable.

\section{Published online: 12 August 2016}

References

1. Posteraro B, Tumbarello M, De Pascale G, Liberto E, Vallecoccia MS, De Carolis E, Di Gravio V, Trecarichi EM, Sanguinetti M, Antonelli M. (1,3)- $\beta$-D-Glucan-based antifungal treatment in critically ill adults at high risk of candidaemia: an observational study. J Antimicrob Chemother. 2016; 71:2262-69

2. Calandra T, Roberts JA, Antonelli M, Bassetti M, Vincent J-L. Diagnosis and management of invasive candidiasis in the ICU: an updated approach to an old enemy. Crit Care. 2016;20(1):125.

3. Cortegiani A, Russotto V, Maggiore A, Attanasio M, Naro AR, Raineri SM, Giarratano A. Antifungal agents for preventing fungal infections in non-neutropenic critically ill patients. Cochrane Database Syst Rev. 2016;1:CD004920.

4. Cortegiani A, Russotto V, Raineri SM, Giarratano A. The paradox of the evidence about invasive fungal infection prevention. Crit Care. 2016;20(1):114.

5. Nucci M, Nouér SA, Esteves $P$, Guimarães $T$, Breda G, Miranda BG de, Queiroz-Telles F, Colombo AL. Discontinuation of empirical antifungal therapy in ICU patients using 1,3- $\beta$-D-glucan. J. Antimicrob Chemother. 2016;dkw188. doi:10.1093/jac/dkw188. 